\title{
Nanomedicine as an emerging approach against intracellular pathogens
}

This article was published in the following Dove Press journal:

International Journal of Nanomedicine

9 December 2011

Number of times this article has been viewed

\author{
Andrea L Armstead ${ }^{1-3}$ \\ Bingyun $\mathrm{Li}^{\mathrm{I}-3}$ \\ 'Biomaterials, Bioengineering \\ and Nanotechnology Laboratory, \\ Department of Orthopedics, School \\ of Medicine, West Virginia University, \\ Morgantown, WV; ${ }^{2}$ Pharmaceutical \\ and Pharmacological Sciences, \\ Health Sciences Center, West \\ Virginia University, Morgantown, \\ WV; ${ }^{3}$ WVNano Initiative, \\ Morgantown, WV, USA
}

\begin{abstract}
Diseases such as tuberculosis, hepatitis, and HIV/AIDS are caused by intracellular pathogens and are a major burden to the global medical community. Conventional treatments for these diseases typically consist of long-term therapy with a combination of drugs, which may lead to side effects and contribute to low patient compliance. The pathogens reside within intracellular compartments of the cell, which provide additional barriers to effective treatment. Therefore, there is a need for improved and more effective therapies for such intracellular diseases. This review will summarize, for the first time, the intracellular compartments in which pathogens can reside and discuss how nanomedicine has the potential to improve intracellular disease therapy by offering properties such as targeting, sustained drug release, and drug delivery to the pathogen's intracellular location. The characteristics of nanomedicine may prove advantageous in developing improved or alternative therapies for intracellular diseases.
\end{abstract}

Keywords: intracellular pathogen, infection, nanomedicine, nanoparticle, drug delivery

\section{Introduction}

Worldwide, a number of diseases (eg, HIV/AIDS [human immunodeficiency virus/ acquired immune deficiency syndrome], hepatitis, and tuberculosis [TB]) are caused by intracellular pathogens. Such diseases can be due to viral, ${ }^{1-8}$ bacterial, ${ }^{9-16}$ fungal, ${ }^{17,18}$ or other parasitic ${ }^{19-21}$ infection, as summarized in Table 1 . The prevalence of each disease may differ geographically, but the intracellular nature of these pathogens, which may protect them from a variety of antibiotic therapies and host immune responses, presents a treatment challenge for the global medical community. Some antibiotic drugs like aminoglycosides and $\beta$-lactams have limited cellular penetration, whereas others such as fluoroquinolones or macrolides have the ability to penetrate host cells but are poorly retained and therefore inefficient. ${ }^{22}$ Therapeutic drugs targeting the intracellular pathogens should overcome the cell membrane barriers and release and retain the drug intracellularly at the therapeutic level for a desired time period. Moreover, multidrug resistance is increasing ${ }^{23-29}$ and is making intracellular disease treatment more challenging. Therefore, there is a need for the development of advanced treatment methods to better control intracellular infections. This review will summarize the status of intracellular disease treatments and the current therapeutic strategies against common intracellular diseases, and present how nanomedicine is emerging as an attractive platform for advanced intracellular drug therapy. Note that therapeutic treatments that tune the cell-mediated immune responses against intracellular pathogens are important but will not be discussed here.
Correspondence: Bingyun Li Associate Professor, Director, Biomaterials, Bioengineering and Nanotechnology Laboratory, Department of Orthopedics, School of Medicine, West Virginia University, Morgantown,

WV 26506-9196, USA

Tel +I 3042931075

Fax +l 3042937070

Email bli@hsc.wvu.edu 
Table I Summary of disease-causing intracellular pathogens

\begin{tabular}{lll}
\hline & Associated disease(s) & References \\
\hline $\begin{array}{l}\text { Viral pathogens } \\
\text { Herpes simplex }\end{array}$ & Type I: oral herpes (cold sore, fever blister) or & Type 2: genital herpes (warts, ulcers) \\
& Liver cirrhosis, hepatocellular carcinoma (HCC) & 1,2 \\
Hepatitis C & Pediatric viral respiratory disease \\
Respiratory syncytial virus & Acquired immunodeficiency syndrome (AIDS) \\
$\begin{array}{l}\text { Human immunodeficiency virus } \\
\text { Bacterial pathogens }\end{array}$ & Tuberculosis \\
$\begin{array}{l}\text { Mycobacterium tuberculosis } \\
\text { Salmonella enterica serovars Typhi, Paratyphi }\end{array}$ & Typhoid fever \\
$\begin{array}{l}\text { Brucella species B. melitensis, B. abortus, B. suis } \\
\text { Listeria monocytogenes }\end{array}$ & Malta fever or undulant fever \\
$\begin{array}{l}\text { Fungal pathogens } \\
\text { Candidia albicans }\end{array}$ & Listeriosis, meningitis in newborn babies \\
& Multiple cutaneous and mucosal forms; frequently \\
Aspergillus fumigatus & encountered oral form is thrush \\
Other pathogens & Pulmonary aspergillosis \\
$\begin{array}{l}\text { Leishmania (parasite) } \\
\text { Plasmodium species (protist) P. vivax, P. ovale, }\end{array}$ & Cutaneous or tegumentary leishmaniasis \\
P. malariae, P. falciparum, P. knowlesi. & Malaria \\
\hline
\end{tabular}

\section{Intracellular pathogens and current treatment approaches}

A wide variety of pathogens are capable of causing intracellular diseases such as HIV/AIDS, hepatitis, and TB (see Table 1). In this section, a brief description of selected viral and bacterial diseases is given along with a discussion of the current therapeutic strategies against the causative pathogens.

\section{Tuberculosis}

TB is a disease caused by Mycobacterium tuberculosis (M. tuberculosis). It is estimated that up to 2.2 billion people carry latent TB infections worldwide. ${ }^{30}$ Exposure to TB does not necessarily lead to an active infection, as normal human immune systems are able to effectively control bacteria, and most people remain in a symptom-free latent stage of infection. ${ }^{30}$ However, susceptible individuals with poor immune response or complicating factors such as HIV infection may develop an active TB infection. ${ }^{31}$ People with active infections typically experience pain in the chest and a cough with blood or sputum (phlegm) lasting more than 3 weeks. ${ }^{32}$ These symptoms could also be accompanied by fatigue, weight loss, fever, chills, or night sweats. ${ }^{33}$ M. tuberculosis is a gram-positive bacterium with a very thick cell wall, which is characteristic of the $\mathrm{Myco}-$ bacterium species. The thick cell wall provides an excellent permeability barrier, making Mycobacteria resistant to a wide variety of antimicrobial agents. ${ }^{23} \mathrm{M}$. tuberculosis bacteria may reside and duplicate within macrophages of the lung. ${ }^{34} \mathrm{~A}$ full description of M. tuberculosis pathogenesis is beyond the scope of this discussion and is reviewed elsewhere. ${ }^{35,36}$ However, an important factor is the bacteria's ability to avoid the cellmediated immune response through granuloma formation, ${ }^{10}$ such that treatment of TB remains a challenge.

At present, the treatment of choice for an active TB infection is long-term antibiotic therapy, with an initial "intensive phase" consisting of the four first-line anti-TB drugs (isoniazid, rifampicin, ethambutol, and pyrazinamide) followed by a typical 4 month course of rifampicin and isoniazid alone. ${ }^{37}$ This has been the most effective treatment to date, although, due to the length of antibiotic therapy, side effects frequently develop ${ }^{38}$ and the cost is high. ${ }^{39}$ These factors may lead to low patient compliance and contribute to the development of drug-resistant bacteria. ${ }^{40}$

\section{HIV}

Infection with HIV is a significant ongoing problem worldwide. As HIV infection progresses, infected individuals develop AIDS. According to the latest statistics from the World Health Organization, there are 33.3 million people living with HIV/AIDS. ${ }^{41}$ Many of those infected live in sub-Saharan Africa, where access to treatment is extremely costly or unavailable. There have been major developments in the treatment of HIV/AIDS since the approval of zidovudine (Retrovir ${ }^{\circledR}$; GlaxoSmithKline, Durham, NC) in $1987 .{ }^{8}$ Current therapeutic efforts consist of a combination of several drugs ${ }^{42}$ typically from different classes of antiviral drugs. ${ }^{43,44}$ This regimen is referred to as highly active antiretroviral therapy (HAART) and has become the standard of care for those infected with HIV. There are five classes of drugs available for HIV/AIDS treatment, including nucleoside 
reverse transcriptase inhibitors, nucleotide reverse transcriptase inhibitors, non-nuceloside reverse transcriptase inhibitors, protease inhibitors, and viral fusion and integrase inhibitors. Typical regimens are combinations of three or four drugs, with subsequent modifications made based on the patient's response to therapy. ${ }^{45}$ Changes made to a patient's regimen are often based on drug resistance testing, and take into consideration toxicity and tolerability of the new treatment strategy. ${ }^{45}$ Although HAART has increased the median survival time of HIV/AIDS patients from less than a year to about 10 years, ${ }^{29}$ patients often develop multidrug-resistant strains of the virus ${ }^{41}$ over the course of therapy, leading to poor treatment outcomes. ${ }^{46}$

\section{Hepatitis $C$ virus}

It is estimated that at least 3 percent of the world's population is infected with the hepatitis $\mathrm{C}$ virus (HCV). ${ }^{3,47}$ The virus affects only humans and is considered a "silent" disease, as infected individuals are usually symptom free until later stages of infection when liver inflammation ${ }^{48}$ occurs. HCV can cause liver scarring and cirrhosis, which ultimately leads to hepatocarcinoma (liver cancer) and death. ${ }^{3,48}$ Unfortunately, there is no effective vaccine ${ }^{49}$ against $\mathrm{HCV}$, and the "gold standard" of HCV treatment is combination antiviral therapy with ribavirin and interferon- $\alpha ;{ }^{4}$ however, both of these compounds are highly toxic and may cause severe side effects. Several months of treatment are usually required to eradicate a chronic infection, and the cost of therapy is high. ${ }^{49}$ These factors contribute to low patient compliance, making therapy less effective and potentially contributing to the development of viral resistance. ${ }^{29}$

\section{Typhoid fever}

Typhoid fever is an acute illness caused by the bacterium Salmonella enterica serovar Typhi (S. Typhi) or Paratyphi, which causes about 20 million cases of illness per year. ${ }^{50}$ These bacteria are usually ingested by consuming contaminated food or water. ${ }^{51}$ Once ingested, the bacteria translocate across intestinal epithelial cells and establish an intracellular growth environment within macrophages. ${ }^{52}$ The bacteria survive within Salmonella-containing vacuoles in infected macrophages and later spread to organs such as the liver and spleen. ${ }^{11,12,53}$ Infected individuals often experience sustained high fevers (up to $103^{\circ} \mathrm{F}$ ), stomach pains, headache, weakness, and appetite loss. ${ }^{51}$ Several vaccines against $S$. Typhi have been developed, ${ }^{54}$ although they provide only short-term protection against the disease due to failure of the immune system to build a lasting response. ${ }^{50,54}$ Typhoid fever is endemic in many developing countries, ${ }^{55}$ where access to vaccines and antibiotic drugs is limited and expensive even if available. Standard treatment for S. Typhi infection is the antibiotic chloramphenicol, although resistance has been reported. ${ }^{50}$ Newer antibiotics like the fluoroquinolones have also proven effective in treating typhoid fever, but the widespread use of these drugs for a range of febrile illnesses in developing countries is contributing to the development of more drug-resistant strains of the bacterium. ${ }^{55}$

\section{Major challenges in treating intracellular pathogens}

Tables 2A and B summarize the common intracellular viruses and bacteria and their related current therapeutic approaches. One can see that intracellular treatment approaches generally involve long-term therapy with a combination of drugs. Side effects can develop due to the drug's inherent toxicity or the length of drug exposure. One of the critical challenges in treating these types of infections is to get enough drugs to reach the pathogens within their intracellular compartments. After reviewing the literature, we found evidence that intracellular pathogens reside in phagosomes, ${ }^{15,34,56}$ vacuoles, ${ }^{52,53}$ cytosol, ${ }^{16,57,58}$ and nucleus, ${ }^{1,59,60}$ and may interact with the Golgi apparatus ${ }^{61}$ and endoplasmic reticulum ${ }^{62-66}$ of host cells (Figure 1). The host cell membranes make it a challenge for many drugs to reach the invading pathogens. Moreover, some antiviral and antibiotic medications have short half-lives, requiring frequent and large doses to obtain a therapeutic effect, which may lead to high cost, low patient compliance, and severe side effects. In addition, drug resistance may be developed when patients do not fully comply with their treatment regimens ${ }^{28}$ or when pathogens are exposed to drugs at suboptimal concentrations ${ }^{67}$ for an extended time period. An alerting new phenomenon is that some pathogens that have traditionally been considered extracellular are emerging as intracellular pathogens and may lead to new types of intracellular diseases. As an example, Staphylococcus aureus (S. aureus) has long been considered an extracellular pathogen, although recent evidence in the literature demonstrates that this bacterium is capable of being internalized and of surviving within host cells (eg, osteoblasts ${ }^{6-72}$ ), and may contribute to recurrent infections. ${ }^{73}$ In order to reduce side effects, improve patient compliance, and reduce the development of drug resistance, more effective therapeutic approaches need to be developed.

An ideal drug treatment method to eradicate intracellular pathogens is one that has the following characteristics: the ability to penetrate host cells and reach the pathogens, high efficacy and low toxicity, and sustained and site-specific drug release. ${ }^{22}$ Recent evidence from the literature shows that nanomedicine is emerging as a promising potential treatment 


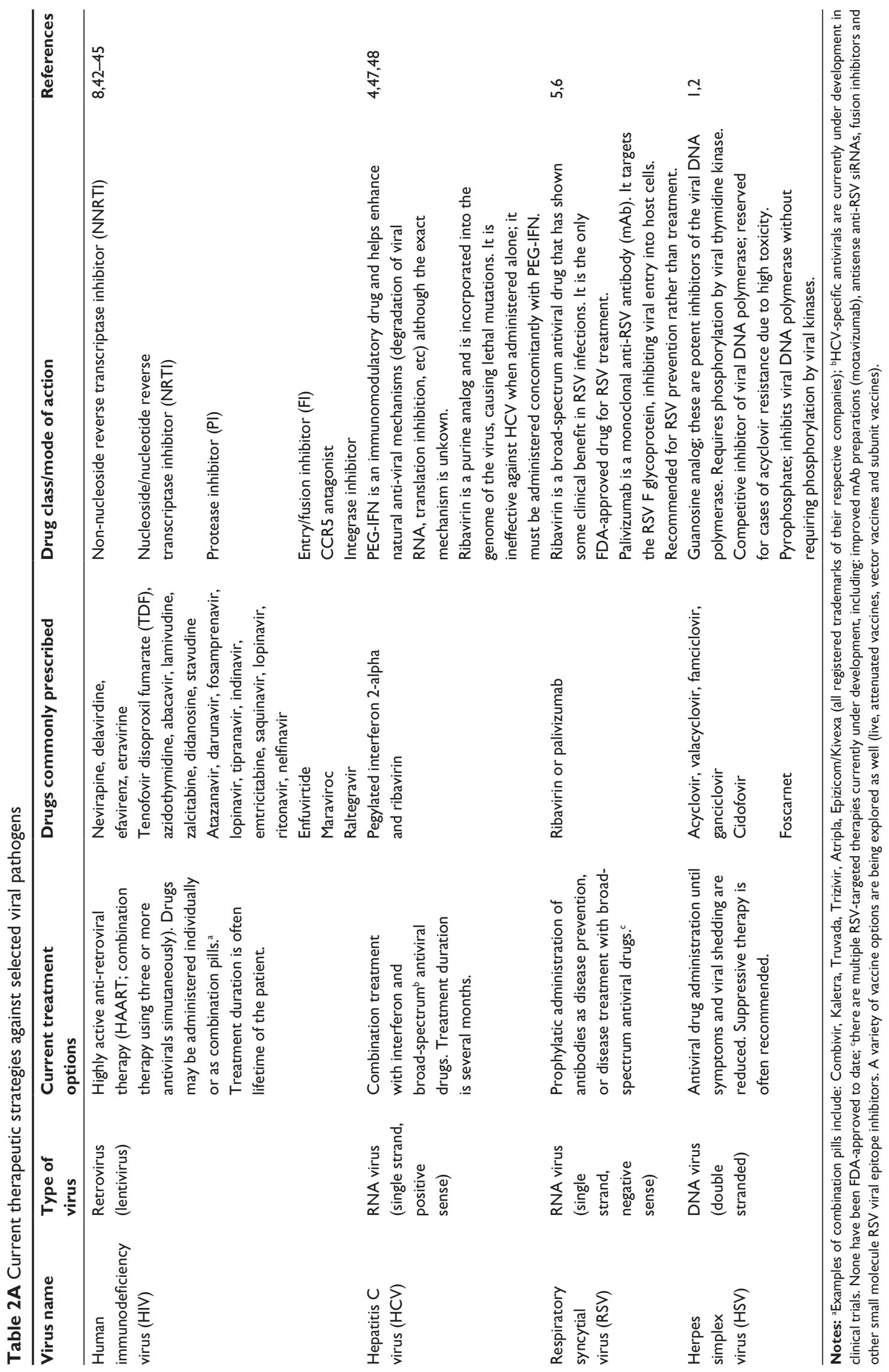




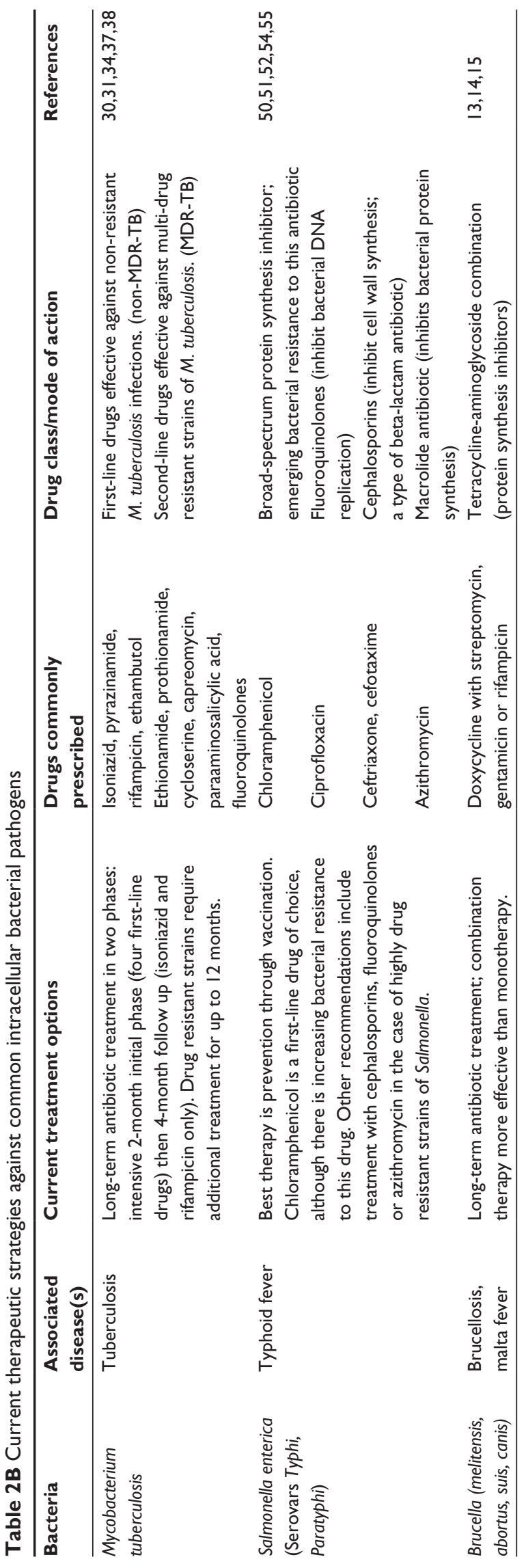

for intracellular pathogens, as nanomedicine has the capacity to address these specific challenges.

\section{Nanomedicine as an emerging therapeutic approach}

Conventional therapies for the treatment of intracellular diseases have existed for many years. These treatments may be further improved as we enter a new era of therapies based on nanomedicine. Nanomedicine can be most succinctly defined as "the application of nanotechnology to medicine." ${ }^{.74}$ There are many potential advantages of using nanomedicine over the conventional therapies previously described. Combining new knowledge of nanomaterials with our current understanding of cellular and molecular functions may allow for the development of novel and advanced nanomedicines. As discussed here, nanomedicine has the capacity to incorporate, encapsulate, or conjugate a variety of drugs in order to target specific cell populations and to offer tunable and site-specific drug release. Nanomedicine could be advantageous in treating intracellular diseases.

\section{Biocompatibility and nanotoxicity}

Biocompatibility is an important feature of any drug delivery system, and the goal is to minimize nonspecific cytotoxic effects to healthy tissues while maximizing drug effects at the target tissue or against invasive pathogens ${ }^{75}$ Nanoparticles have been fabricated using a variety of materials, including poly(lactide-co-glycolide) (PLGA); ${ }^{76-81}$ poly-lactic acid (PLA); ${ }^{77,82,83}$ polymethacrylic acid (PMA); ${ }^{84,85}$ polyethylene glycol (PEG); ;7,86,87 "natural”" polymers such as chitosan, ${ }^{88,89}$ gelatin, ${ }^{90,91}$ or alginate $;{ }^{92,93}$ and other materials such as lipids, ${ }^{94-96}$ gold, ${ }^{75,97}$ and silica. ${ }^{98-101}$

PLGA has been approved by the Food and Drug Administration for several biomedical applications, including surgical sutures, implants, and prosthetic devices. ${ }^{78}$ PLGA micro- or nanoparticles have also been used for a variety of drug delivery applications..$^{79}$ PLGA displays good biocompatibility, biodegradability, suitable degradation kinetics, and mechanical properties and is easy to process. For this reason, PLGA is an attractive candidate for nanoparticle-based drug delivery systems, and there is a large body of ongoing research in this area. Other polymers such as PLA, PMA, PEG, chitosan, gelatin, and alginate also show promise as drug delivery vehicles due to their biocompatible properties. PEG may be used as a "coating" to prevent the rapid removal of nanoparticles from the bloodstream by the mononuclear phagocytic system, which may increase nanoparticle circulation time and theoreti- 


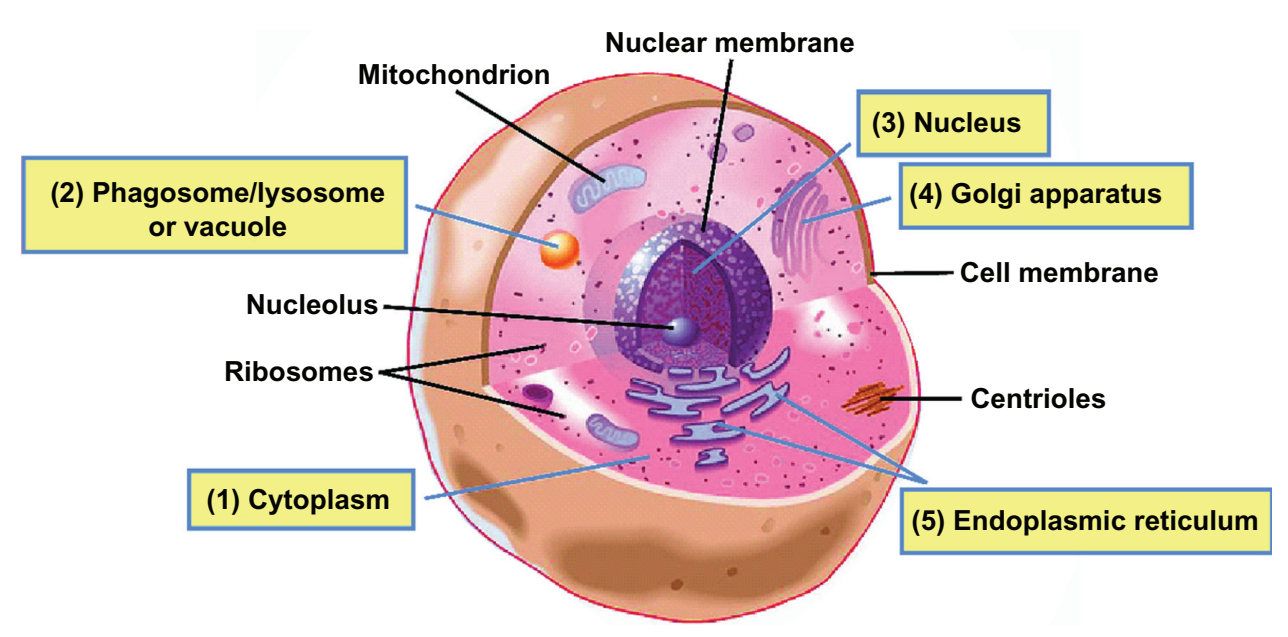

Figure I Potential locations of intracellular pathogens. In a typical eukaryotic cell, pathogens may be internalized via endocytic mechanisms before establishing their intracellular life cycle. Pathogens may reside in various locations, including the cytosol, phagosome, lysosome, or vacuole compartments and the nucleus, and some may

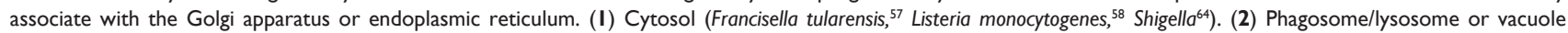
(Mycobacterium tuberculosis, ${ }^{43,45}$ Brucella species, ${ }^{15}$ Salmonella, ${ }^{52,53}$ Legionella ${ }^{56}$ ). (3) Nucleus (herpes simplex virus, ${ }^{1,60}$ HIV $^{59}$ ). (4) Golgi apparatus (Chlamydia ${ }^{61}$ ). (5) Endoplasmic reticulum (hepatitis $C$ virus, ${ }^{65}$ Brucella, ${ }^{63}$ Toxoplasma gondii, ${ }^{66}$ Legionella pneumophilia ${ }^{62,64}$ ).

Note: Reproduced with permission from the Scripps Institution of Oceanography, UCSD.

Abbreviations: HIV, human immunodeficiency virus; UCSD, University of California, San Diego.

cally improve the therapeutic capacity of the nanoparticle. ${ }^{83,86}$ Chitosan and alginate are polymers derived from natural sources and may offer more "friendly" conditions for the encapsulation or incorporation of DNA or peptides, because the use of organic solvents can be avoided. ${ }^{93}$

Lipids are also being explored as potential nanodelivery systems, either as liposomes or lipid nanocapsules (LNCs). Liposomes are composed of lipid bilayers surrounding a hydrophilic "core" and can be designed to incorporate hydrophobic drugs within the lipid bilayer or hydrophilic drugs within the aqueous core. ${ }^{94}$ Liposome-encapsulated aminoglycosides (such as gentamicin) have shown higher therapeutic efficacy than conventional aminoglycoside preparations in the liver and spleen using a murine $S$. typhi infection model. ${ }^{94}$ Amphotericin B (an antifungal) has also been encapsulated in lipids and administered to mice with an Aspergillus fumigatus infection..$^{95}$ Liposome-treated mice have survived longer than mice treated with other amphotericin B preparations, with reduced renal toxicity and a prolonged drug circulation time.$^{95}$ These liposome formulations could be a better treatment for diseases affecting the liver or spleen (eg, typhoid fever, hepatitis). LNCs are another type of lipid-mediated delivery system under exploration. LNCs are considered a "hybrid" between a polymer nanoparticle and a liposome, with an oily core surrounded by a membrane composed of PEGylated surfactants. ${ }^{96}$ LNCs have shown promise in in vitro and some animal models encapsulating anticancer drugs such as paclitaxel, doxorubicin, and etoposide. ${ }^{96}$ The results of these studies have indicated higher intracellular drug delivery and reduced tumor size in vivo when LNC formulations were administered.

In contrast to these "soft" polymer-based nanoparticle systems, metals such as gold have also been explored as potential drug delivery vectors. Gold is an attractive drug delivery vector due to the ease with which biomolecules such as protein or DNA can be attached to the gold surface using thiol chemistry. ${ }^{75}$ This process can also allow attachment of multiple targeting or functional groups to the nanoparticle surface to produce a multifunctional nanoparticle. Although gold nanoparticles can be easily functionalized, these nanoparticles may accumulate in tissues over time because they are not biodegradable. The effects of long-term nanoparticle accumulation are unknown, so in many cases it may be better to use a material that is fully biodegradable. Silica-based compounds are another option, as the biodegradation of silica avoids tissue accumulation concerns, ${ }^{98}$ and it has been demonstrated that a variety of agents have been successfully incorporated into silica-based nanoparticles ${ }^{99-101}$ for drug delivery applications.

Although each of these materials offers its own set of characteristics and biocompatible properties, some materials may be more suited to certain applications than others. It is important to determine the desired properties of the nanomedicine for defined applications.

\section{Cellular penetration and intracellular delivery}

One critical challenge in treating intracellular pathogens is to get enough drugs to reach the pathogen within an intracellular 
compartment. Nanoparticles can be internalized by endocytic mechanisms, which include receptor-mediated or clathrincoated pit endocytosis. ${ }^{102}$ Nanoparticles may reside within acidic endolysosome compartments following endocytosis, ${ }^{79}$ and premature drug release within this acidic compartment may cause drug degradation and render treatment ineffective. It is therefore important for the nanoparticle to escape this compartment and gain access to the cytosol where either the drug cargo may be directly released or the nanoparticle goes on to further target a specific organelle. For instance, PLGA nanoparticles carrying doxorubicin are reportedly capable of escaping the endolysosomal compartment by a reversal of their surface charge. This allows the particles to interact with the membrane and escape into the cytosol where the doxorubicin is released. ${ }^{79}$

There are a number of sources that report time- and concentration-dependent uptake of nanoparticles by a variety of cell types such as smooth muscle cells, ${ }^{79}$ endothelial cells, ${ }^{103,104}$ macrophages, ${ }^{40,105-107}$ and tumor cells. ${ }^{108-113}$ The uptake of PLGA nanoparticles containing bovine serum albumin as a model drug was found to be concentration dependent in human vascular endothelial cells, approaching first-order kinetics. ${ }^{103}$ An in vitro uptake and cellular trafficking study using mesoporous hybrid silica nanoparticles demonstrated that the particles were internalized by receptor-mediated endocytosis, were localized in the endocytic compartment, and then released their cargo within the cytosol. ${ }^{100}$ Another in vitro study examined the uptake of drug-loaded thiolated PMA hydrogel capsules. ${ }^{113}$ The tracking experiments revealed that nanocapsules were taken up by endocytic mechanisms in a time-dependent manner and the drug was released throughout the cell. Collectively, these studies demonstrate that nanoparticles are capable of cellular penetration and intracellular drug release. This is an important characteristic of a nanomedicine that targets intracellular pathogens and promotes direct killing, as the drug must be able to effectively reach the invading pathogens within the intracellular compartment.

\section{Targeting to specific cell types}

The goal of targeting nanomedicines to specific cell populations is to increase the therapeutic efficacy of the drug while minimizing damage to healthy cells and tissues, thereby reducing the incidence and severity of side effects. Currently, the majority of experiments demonstrating the targeting of nanoparticles are related to cancer/tumor targeting, although these same concepts can be applied to pathogen-infected cells and the intracellular compartments ${ }^{98}$ where the pathogens reside.
Nanoparticles can be targeted toward specific cell populations by conjugating targeting ligands to the surface of the nanoparticles. These targeting ligands can be attached directly to nanoparticle surfaces or via a spacer (eg, PEG), which acts to enhance the flexibility of the targeting ligand and increase the likelihood that it will bind the appropriate receptor on the target cell. ${ }^{110,114}$ There are a variety of methods available to attach ligands to nanoparticle surfaces. ${ }^{115,116}$ Targeting ligands can include antibodies (whole or fragment), receptors or receptor ligands, peptides, aptamers, or other small molecules. ${ }^{114} \mathrm{~A}$ few examples are presented here.

When incorporating antibodies on nanoparticle surfaces, it is important to consider whether attachment will affect the binding site or structure of the antibody. Hybrid lipid nanoparticles composed of PLGA, phospholipids, and an outer PEG layer have shown targeting capacity to pancreatic cancer cells when coupled with an anticarcinoembryonic antigen (CEA) half-antibody. ${ }^{112}$ Nanoparticles incubated with CEA-presenting pancreatic cancer cells showed selective uptake of targeted nanoparticles over nontargeted control nanoparticles.

Receptor ligands can also act as targeting moieties. It has recently been reported that nanosized poly(ethylene glycol)-block-poly( $\varepsilon$-caprolactone) (PEG-b-PCL) micelles bearing a surface epidermal growth factor (EGF) have been targeted to breast cancer cells overexpressing the epidermal growth factor receptor (EGFR) in vitro and in vivo. ${ }^{108}$ The uptake of the nanomicelles was two-fold higher using EGFRoverexpressing cells compared with cells that express low levels of EGFR. These results were confirmed using a xenograft mouse model, with mice bearing EGFR-overexpressing tumors demonstrating increased tumor uptake of the particles compared with mice bearing low EGFR-expressing tumors.

Polyester nanoparticles carrying paclitaxel can be targeted to irradiated tumor cells with a short peptide, Gly-Ile-ArgLeu-Arg-Gly (GIRLRG), which binds specifically to GRP78 receptors expressed by glioma and breast tumor cells in response to radiation therapy. ${ }^{109}$ In vitro and in vivo studies were used to compare tumor volumes following treatment with control and targeted nanoparticles. Mice treated with nanoparticles bearing the targeting component had a significant decrease in tumor volume compared with control.

Conjugation of an A10 aptamer to PLGA/PEG nanoparticles has also been shown to be an effective targeting strategy. ${ }^{116}$ The A10 aptamer binds to the prostate-specific membrane antigen (PSMA) on the surface of prostate cancer cells, and the A10 aptamer-conjugated nanoparticles showed higher uptake by PSMA-positive cells than by PSMA-negative cells. 


\section{Site-specific and tunable drug release}

In order to effectively eradicate intracellular pathogens, drugs that are intended to kill the pathogens directly should reach the intracellular locations of infected host cells. As we have summarized in Figure 1, locations may include phagosomes, ${ }^{15,34,56}$ vacuoles, ${ }^{52,53}$ cytosol, ${ }^{16,57,58}$ and nucleus ${ }^{1,59,60}$ and may interact with the Golgi apparatus ${ }^{61}$ or endoplasmic reticulum. ${ }^{62-66}$ With proper engineering and design, nanoparticles can be tailored to carry their drug payloads into the infected cells and then release the drug within specific intracellular compartments. One way to accomplish site-specific drug release is to use $\mathrm{pH}$-responsive polymers. In one study, short peptides were conjugated to $\mathrm{pH}$-responsive polymers designed specifically to disrupt the endosomal membrane at $\mathrm{pH} 5.5$ and subsequently release the peptide into the cytosol. ${ }^{117}$ The polymers had no membrane-disruptive activity at pH 7.4 due to a "masking" PEG group, which is later cleaved to expose the membrane-disruption domain at $\mathrm{pH}$ 5.5. Peptide-polymer conjugates demonstrated a diffuse cytosolic distribution after 1 hour, the time normally required for macrophage endosomes to mature into lysosomes. Unconjugated peptide was located primarily in the lysosome after the same time period, indicating that the peptide itself was unable to escape into the cytosol. This polymer technology may allow for local drug delivery to the cytosol, although it is more critical to reach the specific intracellular location of the pathogen, such as a vacuole or the nucleus.

It has been demonstrated that nanoparticles can be specifically targeted to mitochondria ${ }^{118}$ or nucleus ${ }^{119}$ and may be capable of entering vacuoles ${ }^{120}$ where pathogens such as Salmonella may reside during an infection process. Although intracellular pathogens do not typically live within mitochondria, pathogens such as Listeria monocytogenes can secrete toxins that interfere with normal mitochondrial function. ${ }^{121}$ So the ability to target mitochondria may provide a means to treat these types of infection and attenuate the effects of secreted toxins. One study successfully localized fluorescent nanodiamonds conjugated with mitochondrial protein antibodies to mitochondria in live cells. ${ }^{118}$ The inherent fluorescence of these nanodiamonds allowed for tracking the localization of the nanoparticles, and the microscopy experiments revealed that these nanodiamonds were capable of specifically binding the mitochondria compared with control nanodiamonds without conjugated antibody.

Nuclear targeting has been demonstrated in a similar manner by conjugating nuclear localization signal (NLS) peptides on the surface of PLGA nanoparticles for the nuclear delivery of doxorubicin to cancer cells. ${ }^{119}$ The NLS-targeted nanoparticles demonstrated a six-fold increase in uptake compared with free doxorubicin in solution, and also a 2.5-fold increase in uptake over nontargeted nanoparticles. Cells treated with NLS-targeted nanoparticles also showed a higher toxicity than control nanoparticles, which was expected due to the increased delivery of drug to its nuclear target site. Nuclear targeting would be especially useful in viral infections such as HIV and HSV, as these viruses must enter the nucleus to begin their replicative life cycles.

There is also evidence that demonstrates that nanoparticles loaded with ampicillin are capable of entering cells and delivering the drug within Salmonella-containing vacuoles (SCVs). ${ }^{120}$ Ampicillin was tritium-labeled and found to localize within both the cytosol and SCVs using ultrastructural autoradiography. The colocalization of the drug with the bacteria led to enhanced bacterial killing and elimination compared with control cells treated with ampicillin in solution. The colocalization of the drug within the SCVs is an important step in effectively targeting intracellular pathogen compartments.

Another issue plaguing intracellular pathogen treatments is the lower concentration of drug at the target site and the short duration of efficacy of the drug administered. Large and frequent doses of the drugs are often required to obtain a therapeutic effect. Nanoparticles have the potential to overcome this issue by offering sustained release of drugs, which would lower the required dose and decrease the frequency of administration. ${ }^{122}$ As an example, polymer-based nanoparticles composed of PLGA are able to sustain release of a variety of drugs, such as rolipram for 7 days, ${ }^{123}$ gentamicin for 25 days, ${ }^{124,125}$ and dexamethasone for 15 days. ${ }^{126}$ Hyperbranched poly(amine-ester)-PLGA nanoparticles have also demonstrated sustained release of isoniazid, an important anti-TB drug, up to 14 days. ${ }^{81}$ Another study targeted gelatin nanoparticles loaded with rifampicin, another anti-TB drug, to macrophages. ${ }^{91}$ Test results indicated that the rifampicinloaded gelatin nanoparticles were capable of localizing in the lungs and reducing bacterial loads in a mouse model of TB. In addition, nanoparticle treatment was as effective as traditional daily oral rifampicin at a reduced dosing frequency (every 3 days), due to the sustained release of rifampicin from the gelatin matrix..$^{91}$

\section{Perspectives for the future}

We have reviewed the current therapeutic strategies against commonly encountered intracellular pathogens like viruses and bacteria, and have evaluated the potential of nanomedicine to improve upon the current treatments. When treating 
intracellular diseases, it is important to avoid or prevent further development of pathogen resistance, which is becoming a major problem for the management of TB. ${ }^{23}$ Generally speaking, the success of an antibiotic drug relies on its ability to penetrate the bacterial cell wall and membranes and to bind to its target site (eg, protein, enzyme). ${ }^{127}$ Bacteria may develop resistance by mutating various drug target sites, ${ }^{27}$ and viruses may also develop drug resistance through genetic mutation and recombination events ${ }^{29}$ that can render our current treatments ineffective. For this reason, there is a need for new drugs with novel mechanisms of action that may slow or stop the development of pathogen resistance.

As an example, recent literature has emerged touting the potential of cationic antimicrobial peptides (CAMPs) to serve as an alternative to conventional antibiotic therapy. ${ }^{128-132}$ Antimicrobial peptides are short, positively charged peptides that are produced endogenously by human epithelial tissues where they function to prevent invasion of pathogens, demonstrating broad-spectrum killing activity against bacteria, yeast, and fungi. ${ }^{129,133}$ The complete mechanism of CAMP action is yet to be fully understood, but one proposed mechanism suggests that the CAMPs interact electrostatically with the negatively charged molecules on the outer surface of bacteria, where they can insert themselves into the membrane and form a pore. ${ }^{129}$ Such a disruption in the bacterial cell wall and membranes will affect the osmolytic balance of the bacterium and ultimately cause cell death. Because CAMPs do not have a specific molecular target per se, pathogens may have more difficulty in developing resistance to these peptides. There is also some evidence indicating that CAMPs can help modulate exogenous antibiotic action against several strains of $S$. aureus. ${ }^{134}$ Bacterial cultures treated with both CAMPs and antibiotics had lower antibiotic minimum inhibitory concentration values than for cultures treated with antibiotics alone, indicating complementary action between the CAMPs and antibiotics.

As a result, these CAMPs are attractive targets for the development of novel nanomedicines to treat intracellular diseases. It may be possible to design nanoparticles capable of carrying CAMPs into the cell, or to develop self-assembled CAMP nanoparticles. The development of such nanoparticles may greatly improve intracellular drug therapy by offering high efficacy against a variety of pathogens, and also offer very high biocompatibility, as endogenous CAMPs can be used. We anticipate that CAMP nanoparticles will be a potential advanced nanomedicine for intracellular disease treatments.

Another potential strategy to improve intracellular disease treatments is to take advantage of the preferential accumulation of nanoparticles by the reticuloendothelial system (RES). The RES can also be referred to as the "mononuclear phagocytic system" and is composed of macrophages residing in the liver, spleen, and lungs. Normally, this phenomenon is avoided in nanomedicine, as the RES removes the nanoparticles from circulation and may prevent drugs from reaching target tissues. However, this treatment modality may be particularly useful in treating intracellular diseases such as TB (affecting the lungs) or typhoid fever (affecting the liver and spleen), as these pathogens primarily live and duplicate within macrophages of the affected organs. Using nanoparticles to deliver drugs of interest to fight these diseases may be aided by the natural tendency of these cells to internalize nanoparticles, which would help reduce unnecessary tissue exposure and likely decrease the amount of drug required, because it is being delivered to the appropriate cell.

To create the "perfect" intracellular drug delivery system for fighting infections, certain characteristics of nanoparticles or nanomedicine must be successfully incorporated such that the medicine exhibits acceptable biocompatibility, possesses targeting capacity, and offers efficient and sustained drug release at the target site. Figure 2 illustrates an "ideal" nanoparticle drug delivery system with such characteristics suited to treat intracellular diseases. The nanomaterial used will vary with each application, but there are a variety of biocompatible materials available, as summarized in Table 3. The drug may be used to form the nanoparticle, encapsulated within a polymer matrix, or attached to the surface of a solid "carrier" nanoparticle. The incorporation of surface targeting components to help localize to the affected tissue may improve therapeutic efficacy, along with the presence of molecules to enhance cellular penetration such as cell-penetrating

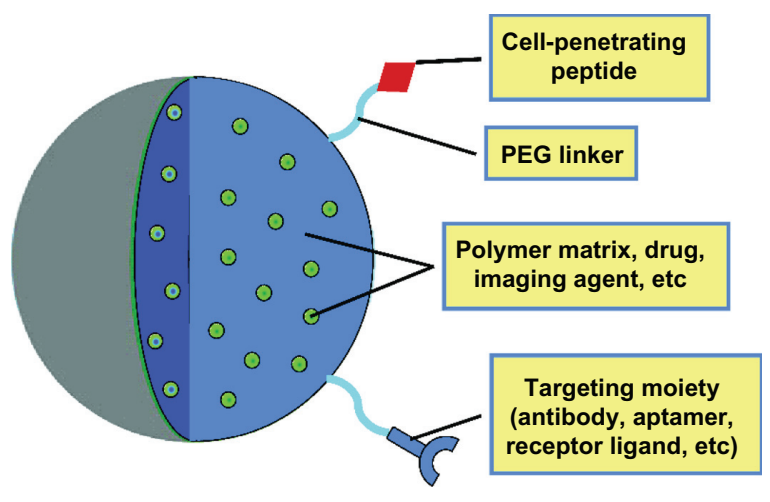

Figure 2 Components of an "ideal" nanoparticle for intracellular drug delivery. The important components of a nanoparticle used for intracellular drug delivery include choice of nanomaterials (eg, polymer, gold), targeting molecules, cellpenetrating peptides (to promote internalization), and the incorporated drug molecules of interest.

Abbreviation: PEG, polyethylene glycol. 
Table 3 Examples of biocompatible nanoparticles discussed in this review

\begin{tabular}{lll}
\hline Type of nanoparticle & Materials used & References \\
\hline $\begin{array}{l}\text { Synthetic or man-made } \\
\text { polymers }\end{array}$ & Poly (lactide-co-glycolide) & $76-81$ \\
& (PLGA) & \\
& Poly-lactic acid (PLA) & $77,82,83$ \\
& Polymethacrylic acid (PMA) & 84,85 \\
& Polyethylene glycol (PEG) & $77,86,87$ \\
Natural polymers & Chitosan & 88,89 \\
& Gelatin & 90,91 \\
Other types & Alginate & 92,93 \\
of nanoparticles & Lipids & $94-96$ \\
& Gold & 75,97 \\
& Silica-based compounds & $98-101$ \\
\hline
\end{tabular}

peptides (CPPs). CPPs are short, cationic peptides, typically derived from the HIV TAT proteins, ${ }^{135}$ which have been shown to readily translocate through cell membranes. The addition of CPPs, such as TAT, to the surface of a nanoparticle can increase the efficiency with which the nanoparticles are delivered intracellularly, ${ }^{136,137}$ although the mechanism by which these CPPs are able to enter cells is currently under debate. It is suggested that either the CPPs promote direct translocation through the membrane via electrostatic interactions or the CPPs bind to specific receptors on the membrane and induce rapid receptor-mediated endocytosis. ${ }^{137}$ In either case, promoting efficient cellular penetration is critical for the treatment of intracellular diseases.

Nanomedicine meets the requirements for an "ideal" drug delivery system to improve intracellular disease therapy; however, we are still exploring this relatively new field. It is early to assess how quickly nanomedicine will be adopted and integrated into mainstream health care. Research on nanomedicine is relatively well funded ${ }^{138}$ so it is likely that many new treatment methods will be approved and available in the future. However, this investment cost for drug development is still high from an economic standpoint, ${ }^{139}$ and the price will probably be passed down to patients via high prescription copays and may not be available for years in developing areas where these improved therapies are needed most. Initially, this may be a deterrent to promoting nanomedicine, but over the long term with new cost-effective technologies, higher drug efficacy, and better treatment outcomes, the price will become acceptable.

\section{Conclusion}

The burden of treating intracellular diseases is continually increasing due to the sheer number of people living with diseases such as HIV/AIDS, hepatitis, and TB worldwide, along with the increasing incidence of drug resistance. We have summarized the locations where these pathogens reside, such as phagosomes, ${ }^{15,33,55}$ vacuoles, ${ }^{51,52}$ cytosol, ${ }^{16,56,57}$ nucleus, ${ }^{1,58,59}$ Golgi apparatus, ${ }^{60}$ and endoplasmic reticulum. ${ }^{61-65}$ The major challenges in treating these invasive pathogens include getting enough drugs to penetrate the host cell and reach the pathogen, having high drug efficacy and low toxicity, and maintaining sustained, site-specific drug release throughout the duration of treatment. In the future, it may be possible to improve disease treatment by utilizing the uptake of nanoparticles by the RES, especially in the case of TB and hepatitis, which affect macrophages. Additionally, looking to endogenous sources such as CAMPs or other immunomodulatory compounds such as interleukins (not covered) may further improve upon current therapies.

The literature presented here shows the potential for nanomedicine to address these challenges and improve upon the current therapeutic strategies. The incorporation of nanomedicine into mainstream health care is a lofty, but achievable, goal. Researchers from multiple disciplines must work together, push the boundaries of science at the nanoscale, and incorporate concepts from biology, engineering, and drug design in order to make this goal a reality.

\section{Acknowledgments}

The authors thank Suzanne Smith and Katherine Hickey for their thoughtful and critical commentary during the manuscript revision process.

\section{Disclosure}

The authors acknowledge financial support from the National Science Foundation (No 1003907), the National Institutes of Health (No HL091456), and WVNano.

\section{References}

1. Akhtar J, Shukla D. Viral entry mechanisms: cellular and viral mediators of herpes simplex virus entry. FEBS J. 2009;276:7728-7736.

2. Wilson SS, Fakiogly E, Herold BC. Novel approaches in fighting herpes simplex virus infections. Expert Rev Anti Infect Ther. 2009;7: 559-568.

3. Alter MJ. Epidemiology of hepatitis c virus infection. World J Gastroenterol. 2007;13:2436-2441.

4. Sharma SD. Hepatitis c virus: molecular biology and current therapeutic options. Indian J Med Res. 2010;131:17-34.

5. Empey KM, Stokes Peebles JR, Kolls JK. Pharmacological advances in the treatment and prevention of respiratory syncytial virus. Clin Infect Dis. 2010;50:1258-1267.

6. Welliver RC. Pharmacotherapy of respiratory syncytial virus. Curr Opin Pharmacol. 2010;10:289-293.

7. Chatterjee K. Host genetic factors in susceptibility to HIV and progression to AIDS. J Genet. 2010;89:109-116.

8. Este JA, Cihlar T. Current status and challenges of antiretroviral research and therapy. Antiviral Res. 2010;85:25-33. 
9. LoBue PS, Enarson DA, Thoen TC. Tuberculosis in humans and its epidemiology, diagnosis and treatment in the United States. Int J Tuberc Lung Dis. 2010;14:1126-1232.

10. Flynn JL, Chan J. Immunology of tuberculosis. Annu Rev Immunol. 2001;19:93-129.

11. Lahiri A, Lahiri A, Iyer N, Das P, Chakravortty D. Visiting the cell biology of salmonella infection. Microbes Infect. 2010;12:809-818.

12. Watson KG, Holden DW. Dynamics of growth and dissemination of Salmonella in vivo. Cell Microbiol. 2010;12:1389-1397.

13. Franco MP, Mulder M, Gilman RH, Smits HL. Human brucellosis. Lancet Infect Dis. 2007;7:775-786.

14. Gamazo C, Lecaroz MC, Prior S, Vitas AI, Campanero MA, Irache JM, et al. Chemical and biological factors in the control of Brucella and brucellosis. Curr Drug Deliv. 2006;3:359-365.

15. Roop RM, Bellair BH, Valderas MW, Cardelli JA. Adaptation of the brucellae to their intracellular niche. Mol Microbiol. 2004;52: 621-630.

16. Theirot JA. The cell biology of infection by intracellular bacterial pathogens. Annu Rev cell Dev Biol. 1995;11:213-239.

17. Lopez-Martinez R. Candidosis, a new challenge. Clin Dermatol. 2010;28:178-184.

18. Balloy V, Chignard M. The innate immune response to Aspergillus fumigatis. Microbes Infect. 2009;11:919-927.

19. Gomez MA, Olivier M. Proteases and phosphatases during Leishmania-macrophage interaction: paving the road for pathogenesis. Virulence. 2010;1:314-318.

20. Goto H, Angelo J, Lindoso L. Current diagnosis and treatment of cutaneous and mucocutaneous leishmaniasis. Expert Rev Anti Infect Ther. 2010;8:419-433.

21. Sadanand S. Malaria: an evaluation of the current state of research on pathogenesis and antimalarial drugs. Yale J Biol Med. 2010;83: 185-191.

22. Briones E, Colino CI, Lanao JM. Delivery systems to increase the selectivity of antibiotics in phagocytic cells. J Control Release. 2008;125:210-227.

23. Chiang CY, Schaaf HS. Management of drug-resistant tuberculosis. Int J Tuberc Lung Dis. 2010;14:672-682.

24. Nguyen HM, Graber CJ. Limitations of antibiotic options for invasive infections caused by methicillin-resistant Staphylococcus aureus: is combination therapy the answer? JAntimicrob Chemother. 2009;65:24-36.

25. Woodford N, Livermore DM. Infections caused by gram-positive bacteria: a review of the global challenge. J Infect. 2009;59 Suppl 1: S4-S16.

26. Finch R. Bacterial resistance-the clinical challenge. Clin Microbiol Infect. 2002;8 Suppl 3:21-32.

27. Hawkey PM, Jones Am. The changing epidemiology of resistance. $J$ Antimicrob Chemother. 2009;64(Suppl 1):3-10.

28. Goossens H. Antibiotic consumption and link to resistance. Clin Microbiol Infect. 2009;15(Suppl 3):12-15.

29. Margeridon-Thermet S, Shafer RW. Comparison of the mechanisms of drug resistance among HIV, hepatitis B and hepatitis $\mathrm{C}$ viruses. Viruses. 2010;2:2696-2739.

30. Kaufman SHE. Future vaccination strategies against tuberculosis: thinking outside the box. Immunity. 2010;33:567-577.

31. Lalloo UG, Ambaram A. New antituberculosis drugs in development. Curr HIV/AIDS Rep. 2010;7:143-151.

32. Signs and symptoms of TB disease. Atlanta, GA: Centers for Disease Control and Prevention; 2010. Available from: http://www.cdc.gov/tb/ topic/basics/signsandsymptoms.htm. Accessed November 10, 2011.

33. Tuberculosis: general information. Atlanta, GA: Centers for Disease Control and Prevention; 2010. Available from: http://www.cdc.gov/tb/ publications/factsheets/general/tb.htm. Accessed November 10, 2011.

34. Ahmad S. Pathogenesis, immunity and diagnosis of latent Mycobacterium tuberculosis infection. Clin Dev Immunol. 2011;2011:814943.

35. Lin PL, Flynn JL. Understanding latent tuberculosis: a moving target. J Immunol. 2010;185:15-22.
36. Kumar D, Rao KVS. Regulation between survival, persistence, and elimination of intracellular mycobacteria: a nested equilibrium of delicate balances. Microbes Infect. 2011;13:121-133.

37. Gaspar M, Cruz A, Fraga A, Castro A, Cruz MEM, Pedrosa J. Developments on drug delivery systems for the treatment of mycobacterial infections. Curr Top Med Chem. 2008;8:579-591.

38. Garner P, Smith H, Munro S, Volmink J. Promoting adherence to tuberculosis treatment. Bull World Health Organ. 2007;85: 404-406.

39. Aspler A, Menzies D, Oxlade O, Banda J, Mwenge L, Godfrey-Faussett P, et al. Cost of tuberculosis diagnosis and treatment from the patient perspective in Lusaka, Zambia. Int J Tuberc Lung Dis. 2008;12: 928-935.

40. Onoshita T, Shimizu Y, Yamaya N, Miyazaki M, Yokoyama M, Fujiwara N, et al. The behavior of PLGA microspheres containing rifampicin in alveolar macrophages. Colloids Surf B Biointerfaces. 2010;76:151-157.

41. Global summary of the AIDS epidemic; 2009. Geneva, Switzerland: World Health Organization; 2009. Available from: http:/www.who.int/ hiv/data/2009_global_summary.png. Accessed November 10, 2011.

42. Wohl DA. Deconstructing most recent antiretroviral recommendations. Curr HIV/AIDS Rep. 2010;7:77-84.

43. Clercq ED. Highlights in the discovery of antiviral drugs: a personal retrospective. J Med Chem. 2010;53:1438-1450.

44. Zolopa AR. The evolution of HIV treatment guidelines: current stateof-the-art of ART. Antiviral Res. 2010;85:241-244.

45. Gupta U, Jain NK. Non-polymeric nano-carriers in HIV/AIDS drug delivery and targeting. Adv Drug Deliv Rev. 2010;62:478-490.

46. Waters L, Nelson M. Why do patients fail HIV therapy? Int J Clin Pract. 2007;61:983-990.

47. Lavanchy D. Evolving epidemiology of hepatitis C virus. Clin Microbiol Infect. 2011;17:107-115.

48. Castello G, Scala S, Palmieri G, Curley SA, Izzo F. HCV-related hepatocellular carcinoma: from chronic inflammation to cancer. Clin Immunol. 2010;130:237-250.

49. Yu CI, Chiang BL. A new insight into hepatitis $\mathrm{C}$ vaccine development J Biomed Biotechnol. 2010;2010:548280.

50. Zhang XL, Jeza VT, Pan Q. Salmonella typhi: from a human pathogen to a vaccine vector. Cell Mol Immunol. 2008;5:91-97.

51. Typhoid fever: general information. Atlanta, GA: Centers for Disease Control and Prevention; 2010. Available from: http://www. cdc.gov/nczved/divisions/dfbmd/diseases/typhoid_fever. Accessed November 10, 2011.

52. Trebichavsky I, Splichal I, Splichalova A. Innate immune response in the gut against Salmonella-review. Folia Microbiol. 2010;55:295-300.

53. Buchmeier NA, Heffron F. Inhibition of macrophage phagosomelysosome fusion by Salmonella typhimurium. Infect Immun. 1991;59: 2232-2238.

54. Guzman CA, Borsutzky S, Giot-Went M, Metcalfe IC, Pearman J, Collioud A, et al. Vaccines against typhoid fever. Vaccine. 2006;24: 3804-3811.

55. Thaver D, Zaidi AKM, Critchley J, Azmatullah A, Madni SA, Butta ZA. A comparison of fluoroquinolones versus other antibiotics for treating enteric fever: meta-analysis. BMJ. 2009;338:b1865.

56. Lawlor C, Kelly C, O’Leary S, O’Sullivan MP, Gallagher PJ, Keane J, et al. Cellular targeting and trafficking of drug delivery systems for the prevention and treatment of MTb. Tuberculosis. 2010;91: 93-97.

57. Al-Khodor S, Kwalk YA. Triggering Ras signaling by intracellular Francisella tularensis through recruitment of PKC-alpha and beta-I to the SOS2/GrB2 complex is essential for bacterial proliferation in the cytosol. Cell Microbiol. 2010;12:1604-1621.

58. Collins CA, Brown EJ. Cytosol as a battle ground: ubiquitination as a weapon for both host and pathogen. Trends Cell Biol. 2010;20: 205-213.

59. D’Orsogna MR, Chou T. Optimal cytoplasmic transport in viral infections. PLoS One. 2009;4:8165-8172. 
60. Calder JM, Stow EC, Stow ND. On the cellular localization of the components of the herpes simplex virus type. 1 helicase-primase complex and the viral origin-binding protein. J Gen Virol. 1992;73:531-538.

61. Heuer D, Lipinski AR, Machuy N, Karlas A, Wehrens A, Siedler F, et al. Chlamydia causes fragementation of the golgi compartment to ensure reproduction. Nature. 2009;457:731-735.

62. Tilney LG, Harb OS, Connelly PS, Robinson CG, Roy CR. How the parasitic bacterium Legionella pneumophilia modifies its phagosome and transforms it into rough ER: implications for conversion of plasma membrane to the ER membrane. J Cell Sci. 2001;114:4637-4650.

63. Celli J, Chastellier C, Franchini DM, Pizaroo-Cerda J, Moreno E, Gorvel JP. Brucella evades macrophage killing via VirB-dependent sustained interactions with the endoplasmic reticulum. $J$ Exp Med. 2003;198:545-556.

64. Roy CR, Salcedo SP, Gorvel JPE. Pathogen-endoplasmic reticulum interactions: in through the out door. Nat Rev immunol. 2006;6: 136-147.

65. Moradpour D, Gosert R, Egger D, Penin F, Blum HE, Bienz K. Membrane association of hepatitis $\mathrm{C}$ virus nonstructural proteins and identification of the membrane alteration that harbors the viral replication complex. Antiviral Res. 2003;60:103-109.

66. Sinai AP, Webster P, Joiner KA. Association of host cell endoplasmic reticulum and mitochondria with the Toxoplasma gondii parasitophorous vacuole membrane: a high affinity interaction. J Cell Sci. 1997;110:2117-2128.

67. Sandegren L, Andersson DI. Bacterial gene amplification: implications for the evolution of antibiotic resistance. Nat Rev Microbiol. 2009; 7:578-588.

68. Sendi P, Proctor RA. Staphylococcus aureus as an intracellular pathogen: the role of small colony variants. Trends Microbiol. 2009;17:54-58.

69. Garzoni C, Kelly WL. Staphylococcus aureus: new evidence for intracellular persistence. Trends Microbiol. 2009;17:59-65.

70. Hudson MC, Ramp WK, Nicholson NC, Williams AS, Nousiainen MT. Internalization of Staphylococcus aureus by cultured osteoblasts. Microb Pathog. 1995;19:409-419.

71. Jevon M, Guo C, Ma BC, Mordan N, Nair SP, Harris M, et al. Mechanisms of internalization of Staphylococcus aureus by cultured human osteoblasts. Infect Immun. 1999;67:2677-2681.

72. Sinha B, Fraunholz M. Staphylococcus aureus host cell invasion and post-invasion events. Int J Med Microbiol. 2010;300:170-175.

73. Ellington J, Harris M, Webb L, Smith B, Smith T, Tan K, et al. Intracellular Staphylococcus aureus: a mechanism for the indolence of osteomyelitis. J Bone Joint Surg Br. 2003;85:918-921.

74. Freitas RA. What is nanomedicine? Nanomedicine. 2005;1:2-9.

75. Seale-Goldsmith MM, Leary JF. Nanobiosystems. Nanomed Nanobiotechnol. 2009;1:553-567.

76. Astete CE, Savliov CM. Synthesis and characterization of PLGA nanoparticles. J Biomater Sci Polymer Edn. 2006;17:247-289.

77. Avgoutstakis K. Pegylated poly(lactide) and poly(lactide-co-glycolide) nanoparticles: preparation, properties and possible applications in drug delivery. Curr Drug Deliv. 2004;1:321-333.

78. Lu JM, Wang X, Marin-Muller C, Wang H, Lin PH, Yao Q, et al. Current advances in research and clinical application of PLGA-based nanotechnology. Expert Rev Mol Diagn. 2009;9:325-341.

79. Panyam J, Zhou WZ, Prabha S, Sahoo SK, Labhasetwar V. Rapid endolysosomal escape of poly(DL-lactide-co-glycolide) nanoparticles: implications for drug and gene delivery. FASEB J. 2002;16:1217-1226.

80. Qaddoumi MG, Ueda H, Yang J, Davda J, Labhasetwar V, Lee VHL. The characteristics and mechanisms of uptake of PLGA nanoparticles in rabbit conjunctival epithelial cell layers. Pharm Res. 2004;21: 641-648.

81. Kohane DS, Tse JY, Yeo Y, Padera R, Shubina M, Langer R. Biodegradable polymeric microspheres and nanospheres for drug delivery in the peritoneum. J Biomed Mater Res. 2006;77A:351-361.

82. Wang G, Liu SJ, Ueng SW, Chan EC. The release of cefazolin and gentamicin from biodegradable PLA/PGA beads. Int J Pharm. 2004;273:203-212.
83. Xiao RZ, Zeng ZW, Zhou GL, Wang JJ, Li FZ, Wang AM. Recent advances in PEG-PLA block copolymer nanoparticles. Int $J$ Nanomedicine. 2010;5:1057-1065.

84. Lorenz S, Hauser CP, Autenrieth B, Weiss CK, Landfester K, Mailander V. The softer and more hydrophobic the better: influence of the side chain of polymethacrylate nanoparticles for cellular uptake. Macromol Biosci. 2010;10:1034-1042.

85. Sajeesh S, Sharma CP. Cyclodextrin-insulin complex encapsulated in polymethacrylic acid based nanoparticles for oral insulin delivery. Int J Pharm. 2006;325:147-154.

86. Joralemon MJ, McRae S, Emrick T. PEGylated polymers for medicine: from conjugation to self-assembled systems. Chem Comm. 2010; 46:1377-1393.

87. Vlerken LE, Vyas TK, Amiji MM. Poly(ethylene glycol)-modified nanocarriers for tumor-targeted and intracellular delivery. Pharm Res. 2007;24:1405-1415.

88. Panos I, Acosta N, Heras A. New drug delivery systems based on chitosan. Curr Drug Discov Technol. 2008;5:333-341.

89. Park JH, Saravanakumar G, Kim K, Kwon IC. Targeted delivery of low molecular drugs using chitosan and its derivatives. Adv Drug Deliv Rev. 2009;62:28-41.

90. Kumari A, Yadav SK, Yadav SC. Biodegradable polymers nanoparticles based drug delivery systems. Colloids Surf B Biointerfaces. 2010;75:1-18

91. Saraogi GK, Gupta P, Gupta UD, Jain NK, Agrawal GP. Gelatin nanocarriers as potential vectors for effective management of tuberculosis. Int J Pharm. 2009;385:143-149.

92. Hamidi M, Azadi A, Rafiei P. Hydrogel nanoparticles in drug delivery. Adv Drug Deliv Rev. 2008;60:1638-1649.

93. Reis CP, Neufeld RJ, Vilela S, Ribeiro AJ, Veiga F. Review and current status of emulsions/dispersions technology using an internal gelation process for the design of alginate particles. J Microencapsul. 2006;23:245-257.

94. Schiffelers R, Storm G, Bakker-Woudenberg I. Liposome-encapsulated aminoglycosides in pre-clinical and clinical studies. JAntimicrob Chemother. 2001;48:333-334.

95. Jung SK, Lim DH, Jung SH, Lee JE, Jeong KS, Seong H, et al. Amphotercin B-entrapping lipid nanoparticles and their in vitro and in vivo characteristics. Eur J Pharm Sci. 2009;37:313-320.

96. Huynh NT, Passirani C, Saulnier P, Benoit JP. Lipid nanocapsules: a new platform for nanomedicine. Int J Pharm. 2009;379:201-209.

97. Pissuwan D, Cortie CH, Balenzuela SM, Cortie MB. Functionalized gold nanoparticles for controlling pathogenic bacteria. Trends Biotechnol. 2010;28:207-213.

98. Seleem MN, Munusamy P, Ranjan A, Alqublan H, Pickrell G, Sriragnanathan N. Silica-antibiotic hybrid nanoparticles for targeting intracellular pathogens. Antimicrob Agents Chemother. 2009;53: $4270-4274$.

99. Izquierdo-Barba I, Vallet-Regi M, Kupferschmidt N, Terasaki O, Schmidtchen A, Malmsten M. Incorporation of antimicrobial compounds in mesoporous silica film monolith. Biomaterials. 2009;30:5729-5736.

100. Rosenholm JM, Peuhu E, Eriksson JE, Sahlgren C, Linden M. Targeted intracellular delivery of hydrophobic agents using mesoporous hybrid silica nanoparticles as carrier systems. Nano Lett. 2009;9:3308-3311.

101. Wan X, Wang D, Liu S. Fluorescent pH-sensing organic/inorganic hybrid mesoporous silica nanoparticles with tunable redox-responsive release capacity. Langmuir. 2010;26:15574-15579.

102. Vasir JK, Labhasetwar V. Biodegradable nanoparticles for cytosolic delivery of therapeutics. Adv Drug Deliv Rev. 2007;59:718-728.

103. Davda J, Labhasetwar V. Characterization of nanoparticle uptake by endothelial cells. Int J Pharm. 2002;233:51-59.

104. Ferrati S, Mack A, Chiappini C, Liu X, Bean AJ, Ferrari M, et al. Intracellular trafficking of silicon particles and logic-embedded vectors. Nanoscale. 2010;2:1512-1520.

105. Martins M, Viveiros M, Couto I, Amaral L. Targeting human macrophages for enhanced killing of intracellular XDR-TB and MDR-TB. Int J Tuberc Lung Dis. 2009;13:569-573. 
106. Lecaroz C, Blanco-Prieto MJ, Burrell MA, Gamazo C. Intracellular killing of Brucella melitensis in human macrophages with microsphere encapsulated gentamicin. J Antimicrob Chemother. 2006;58: 549-556.

107. Kamat M, El-Boubbou K, Zhu DC, Lansdell T, Lu X, Li W, et al Hyaluronic acid immobilized magnetic nanoparticles for active targeting and imaging of macrophages. Bioconj Chem. 2010;21: 2128-2135

108. Lee H, Fonge H, Joang B, Reilly RM, Allen C. The effects of particle size and molecular targeting on the intratumoral and subcellular distribution of polymeric nanoparticles. Mol Pharm. 2010;7:1195-1208.

109. Passarella RJ, Spratt DE, van der Ende AE, Phillips JG, Wu H, Sathiyakumar V, et al. Targeted nanoparticles that deliver a sustained, specific release of paclitaxel to irradiated tumors. Cancer Res. 2010;70:4550-4559.

110. Ruoslahti E, Bhatia SN, Sailor MG. Targeting of drugs and nanoparticles to tumors. J Cell Biol. 2010;188:759-769.

111. Vazquez E, Cubasri R, Unzueta U, Roldan M, Domingo-Espan J, Ferrer-Miralles N, et al. Internalization and kinetics of nuclear migration of protein-only, arginine-rich nanoparticles. Biomaterials. 2010; 31:9333-9339.

112. Hu CMJ, Kaushal S, Cao HST, Aryal S, Sartor M, Esener D, et al. Half-antibody functionalized lipid-polymer hybrid nanoparticles for targeted drug delivery to carcinoembryonic antigen presenting pancreatic cancer cells. Mol Pharm. 2010;7:914-920.

113. Yan Y, Johnston APR, Dodds AJ, Kamphuis MMJ, Ferguson C, Parton RG, et al. Uptake and intracellular fate of disulfide-bonded polymer hydrogel capsules for doxorubicin delivery to colorectal cancer cells. ACS Nano. 2010;4:2928-2936.

114. Wang M, Thanou M. Targeting nanoparticles to cancer. Pharmacol Res. 2010;62:90-99.

115. Nobs L, Buchegger F, Gurny R, Allemann E. Current methods for attaching targeting ligands to liposomes and nanoparticles. $J$ Pharm Sci. 2007;90:1980-1992.

116. Gu F, Zhang L, Teply BA, Mann N, Wang A, Radovic-Moreno AF, et al. Precise engineering of targeted nanoparticles by using selfassembled biointegrated block copolymers. Proc Natl Acad Sci U SA. 2008; 105:2586-2591.

117. Murthy N, Campbell J, Fausto N, Hoffmann AS, Stayton PS. Bio-inspired $\mathrm{pH}$-responsive polymers for the intracellular delivery of biomolecular drugs. Bioconj Chem. 2003;14:412-419.

118. Mkandawire M, Pohl A, Gubarevich T, Lapina V, Applehans D, Rodel G, et al. Selective targeting of green fluorescent nanodiamond conjugates to mitochondria in HeLa cells. J Biophotonics. 2009;2:596-606.

119. Misra R, Sahoo SK. Intracellular trafficking of nuclear localization signal conjugated nanoparticles for cancer therapy. Eur J Pharm Sci. 2010;39:152-163.

120. Balland O, Pinto-Alphandar H, Viron A, Puvion E, Andremont A, Couvreur P. Intracellular distribution of ampicillin in murine macrophages infected with Salmonella typhimurium and treated with $\left({ }^{3} \mathrm{H}\right)$ ampicillin-loaded nanoparticles. J Antimicrob Chemother. 1996;37: 105-115.

121. Stavru F, Bouillaud F, Sartori A, Ricquier D, Cossart P. Listeria monocytogenes transiently alters mitochondrial dynamics during infection. Proc Natl Acad Sci U SA. 2011;108:3612-3617.
122. Zhang L, Gu FX, Chan JM, Wang AZ, Langer RS, Farokhzad OC. Nanoparticles in medicine: therapeutic applications and developments. Clin Pharmacol Ther. 2008;83:761-769.

123. Lamprecht A, Ubrich N, Yamamoto H, Schafer U, Takeuchi H, Maincent $\mathrm{P}$, et al. Biodegradable nanoparticles for targeted drug delivery in treatment of inflammatory bowel disease. $J$ Pharmacol Exp Ther. 2001;299:775-781.

124. Lecaroz C, Gamazo C, Renedo MJ, Blanco-Prieto MJ. Biodegradable micro- and nanoparticles as long-term delivery vehicles for gentamicin. J Microencapsul. 2006;23:782-792.

125. Blanco-Prieto MJ, Lecaroz C, Renedo MG, Kunkova J, Gamazo C. In vitro evaluation of gentamicin released from microparticles. Int $J$ Pharm. 2002;242:203-206.

126. Panyam J, Labhasetwar V. Sustained cytoplasmic delivery of drugs with intracellular receptors using biodegradable nanoparticles. Mol Pharm. 2004;1:77-84.

127. Cloutier MJ. Antibiotics: mechanisms of action and the acquisition of resistance-when magic bullets lose their magic. Am J Pharm Educ. 1995;59:167-172.

128. Wang H, Xu K, Liu L, Tan JPK, Chen Y, Li Y, et al. The efficacy of self-assembled cationic antimicrobial peptides nanoparticles against Cryptococcus neoformans for the treatment of meningitis. Biomaterial. 2010;31:2874-2881

129. Bucki R, Leszczynska K, Namiot A, Solokowski W. Calthelicidin LL-37: a multitask antimicrobial peptide. Arch Immunol Ther Exp. 2010;85:15-25.

130. Eby DM, Farrington KE, Johnson GR. Synthesis of bioinorganic antimicrobial peptide nanoparticles with potential therapeutic properties. Biomacromolecules. 2008;9:2481-2494.

131. Liu L, Xu K, Wang H, Tan JPK, Fan W, Venkatraman SS, et al. Self-assembled cationic peptide nanoparticles as an efficient antimicrobial agent. Nat Nanotechnol. 2009;4:457-463.

132. Cho WM, Joshi BP, Cho H, Lee KH. Design and synthesis of novel antibacterial peptide-resin conjugates. ACS Med Chem Lett. 2007; 17:5772-5776

133. Durr UHN, Sudheendra US, Ramamoorthy A. LL-37, the only human member of the cathelicidin family of antimicrobial peptides. Biochim Biophys Acta. 2006;1758:1408-1425.

134. Leszczynska K, Namiot A, Hanmey PA, Bucki R. Modulation of exogenous antibiotic activity by host cathelicidin LL-37. APIMS. 2010;118:830-836

135. Fonseca SB, Pereira MP, Kelley SO. Recent advances in the use of cell-penetrating peptides for medical and biological applications. $A d v$ Drug Deliv Rev. 2009;61:953-964.

136. Juliano RL, Alam R, Dixit V, Kang HM. Cell-targeting and cell-penetrating peptides for delivery of therapeutic and imaging agents. Wiley Interdiscip Rev Nanomed Nanobiotechnol. 2009;1(3): 324-335.

137. Schmidt N, Mishra A, Lai GH, Wong GCL. Arginine-rich cellpenetrating peptides. FEBS Lett. 2010;584:1806-1813.

138. Murday JS, Siegel RW, Stein J, Wright JF. Translational nanomedicine: status assessment and opportunities. Nanomedicine NBM 2009;5:251-273.

139. Allhoff F. The coming era of nanomedicine. Am J Bioeth. 2009; 9(10):3-11.
International Journal of Nanomedicine

\section{Publish your work in this journal}

The International Journal of Nanomedicine is an international, peerreviewed journal focusing on the application of nanotechnology in diagnostics, therapeutics, and drug delivery systems throughout the biomedical field. This journal is indexed on PubMed Central, MedLine, CAS, SciSearch ${ }^{\circledR}$, Current Contents ${ }^{\circledR} /$ Clinical Medicine,

\section{Dovepress}

Journal Citation Reports/Science Edition, EMBase, Scopus and the Elsevier Bibliographic databases. The manuscript management system is completely online and includes a very quick and fair peer-review system, which is all easy to use. Visit http://www.dovepress.com/ testimonials.php to read real quotes from published authors. 